\title{
Unusual splenic sinusoidal iron overload in sickle cell/ haemoglobin D-Punjab disease
}

\author{
P M C Jiskoot, C Halsey, R Rivers, B J Bain, B S Wilkins
}

J Clin Pathol 2004;57:539-540. doi: 10.1136/¡icp.2002.004481

Sickle cell/haemoglobin D-Punjab disease is a disorder with similar clinical features to sickle cell anaemia. This report describes the case of an 11 year old boy with this disease who was treated with regular transfusions from infancy. He underwent splenectomy at the age of 10 years for hypersplenism. Histology of the spleen revealed a striking pattern of heavy sinusoidal endothelial iron loading, with only moderate uptake by macrophages. Possible explanations for this unusual distribution of iron include phagocytosis of sickled erythrocytes by sinusoidal endothelial cells or direct endothelial iron uptake via transferrin receptors. Transfusion programmes ameliorate the symptoms of sickle cell disease but the dangers of iron overload should always be remembered.

$\mathrm{S}$ ickle cell/haemoglobin D-Punjab disease (SD disease) is a rare sickling disorder. The clinical phenotype closely resembles that of sickle cell anaemia. We describe the case of an 11 year old boy with SD disease on a regular blood transfusion programme. Splenectomy was performed at the age of 10 for progressive hypersplenism. Despite a history of regular iron chelation treatment, splenic histology showed evidence of profound iron overload. The dangers of iron overload are well recognised in children with thalassaemia, but less so in other hereditary haemolytic anaemias.

\section{CASE HISTORY}

Our patient is the second child of unrelated parents, both originating from southern Turkey. He had presented to his local hospital in Turkey at the age of 2 months with anaemia and hepatosplenomegaly. A diagnosis of "Mediterranean anaemia" was made and a transfusion programme was begun. At the age of 2 years he moved to the UK with his family who brought him to our hospital requesting transfusion. At that time, he was clinically well with mild jaundice, splenomegaly $(5 \mathrm{~cm}$, palpable), and hepatomegaly $(3 \mathrm{~cm}$, palpable). Haemoglobin electrophoresis showed bands in the positions of haemoglobins S $(24 \%)$ and A. Parental studies showed his father to be a carrier of haemoglobin $S$ and his mother to be a carrier of haemoglobin D-Punjab. Subsequent studies, when he was not receiving transfusions, confirmed that the haemoglobin A was transfusion derived, and a diagnosis of SD disease was made. This was confirmed by molecular analysis, which showed haemoglobin D-Punjab (Los Angeles) ( $\beta 121 \mathrm{glu} \rightarrow \mathrm{gln}$ ). Bone marrow examination at presentation showed sickle cells, erythroid hyperplasia, and mild dyserythropoiesis. Electron microscopy showed no evidence of congenital dyserythropoietic anaemia. There was no evidence of $\alpha$ or $\beta$ thalassaemia trait or a red cell membrane defect in the patient or other family members. Glucose-6-phosphate dehydrogenase and pyruvate kinase assays were normal.
Transfusions continued and iron chelation with subcutaneous desferrioxamine was started (escalating doses up to $60 \mathrm{mg} / \mathrm{kg} /$ day, given over 10-12 hours, six nights/week). Despite chelation treatment, the child's serum ferritin rose to $3000 \mu \mathrm{g} /$ litre. At 9 years of age, his transfusion requirement rose rapidly to $30 \mathrm{ml}$ of packed cells/kg every three to four weeks. This was accompanied by increasing splenomegaly, mild leucopenia, and thrombocytopenia. Isotope imaging with technetium-99m labelled red blood cells showed an increased splenic red blood cell pool (19.9\% of total red blood cell volume), with filling defects suggesting previous splenic infarction.

Splenectomy was performed at the age of 10 years. He has remained transfusion independent since then, with a haemoglobin concentration of 70-80 g/litre. Moderate vasoocclusive crises developed on stopping the transfusion programme.

\section{SPLENIC PATHOLOGY}

The spleen weighed $405 \mathrm{~g}$ (mean normal spleen weight for a 10 year old boy, $110 \mathrm{~g} ; \mathrm{SD}, 30)$ and showed several areas of recent infarction. The cut surface had an unusual tan colour.

Histologically, the white pulp appeared reactive but was otherwise unremarkable. The red pulp was expanded with widened cords and prominent sinuses. Sickled cells were visible in infarcted areas (fig 1A). Sinusoidal (but not capillary or larger vessel) endothelial cells showed striking haemosiderin loading, which was confirmed by Perls' staining (fig 1B) and ultrastructural examination (fig 2). Cordal and intrasinusoidal macrophages showed moderate iron loading.

\section{DISCUSSION}

SD disease is a sickling disorder that is at least as severe as sickle cell anaemia. The usual clinical features of this condition were completely suppressed in our patient by regular transfusion from an early age.

Macrophage iron loading is well recognised in patients with haemolytic anaemia or transfusional iron overload. However, the sinusoid endothelial iron loading in this patient is highly unusual. Possible explanations include direct phagocytosis of sickled cells or iron uptake via transferrin receptors.

In support of the first theory, cells from patients with sickle cell disease are known to undergo sickling in the hypoxic environment of the spleen, and sickled cells adhere to upregulated adhesion molecules on endothelial cells. ${ }^{1}$ Although phagocytosis in sickling disorders has not been demonstrated, splenic sinusoidal endothelial cells have been shown to phagocytose red blood cells in cases of hereditary spherocytosis and autoimmune haemolytic anaemia. ${ }^{2}{ }^{3}$ Direct uptake of iron by endothelial cells is also possible, because

Abbreviations: SD, sickle cell/haemoglobin D-Punjab 


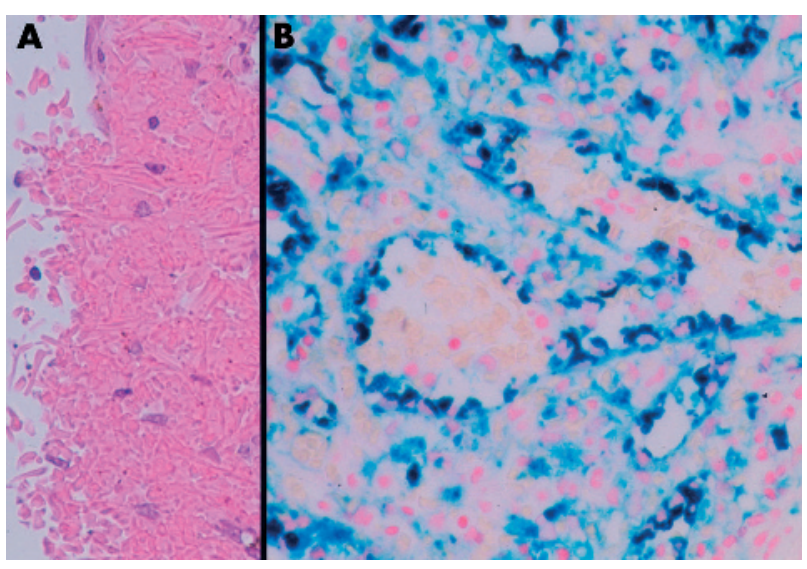

Figure 1 (A) Sickled cells in splenic red pulp, haematoxylin and eosin stain. (B) Iron loading of splenic sinusoidal endothelial cells, Perls' stain.

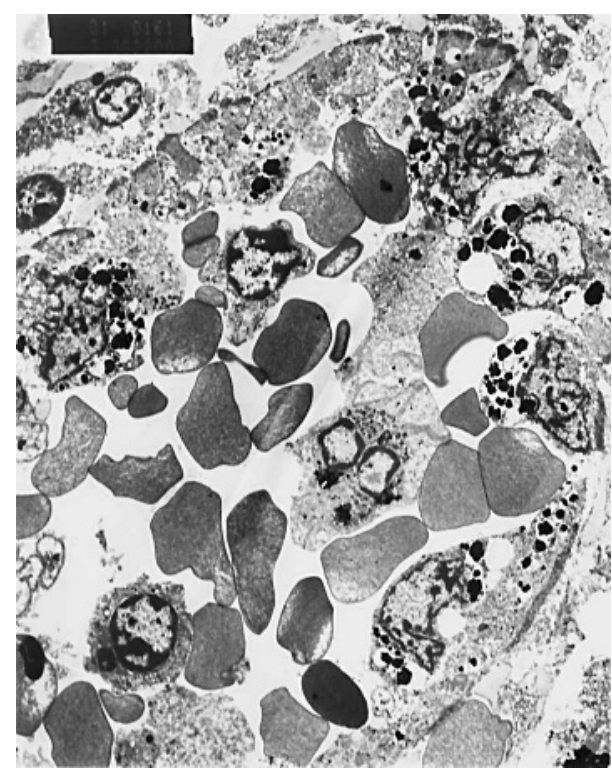

Figure 2 Ultrastucture of a splenic sinusoid showing deformed red blood cells and haemosiderin granules within endothelial cells. Electron micrograph of formalin fixed, resin embedded splenic tissue. Original magnification, $\times 480$.

transferrin receptors have been demonstrated on splenic sinusoidal cells. ${ }^{4}$

It has been speculated that splenic sinus lining cells (also known as littoral cells) have hybrid properties of endothelial cells and macrophages. In addition to transferrin receptors, splenic sinusoidal endothelial cells and littoral cell angiomas derived from them have been shown to express CD68. ${ }^{5}$ This has been taken as evidence of a hybrid endothelialmacrophage cell type. However, in the absence of the direct observation of phagocytic activity, such immunohistochemical evidence is circumstantial. Transferrin receptors are found on a wide range of proliferating cells and CD68 is a lysosomal antigen found in many cell types, including some epithelia. Nonetheless, splenic sinusoidal endothelial cells are undoubtedly highly unusual, apparently unique in the human body. Among their unusual properties as endothelial

\section{Take home messages}

- We report an 11 year old boy with sickle cell/ haemoglobin D-Punjab disease, treated with regular transfusions from infancy, who underwent splenectomy at the age of 10 for hypersplenism

- Histology of the spleen revealed a striking pattern of heavy sinusoidal endothelial iron loading, perhaps as a result of phagocytosis of sickled erythrocytes by sinusoidal endothelial cells or direct endothelial iron uptake via transferrin receptors

- This case highlights the fact that although transfusion programmes ameliorate the symptoms of sickle cell disease, the dangers of iron overload should always be remembered

cells, they lack expression of CD34 but express CD8 and BCL2. Intense, selective haemosiderin accumulation by these cells in our patient's spleen is certainly compatible with phagocytic potential, although we found no visible evidence of ingested sickle cells within the sinusoidal endothelium.

Recent studies suggest that alternative treatments such as hydroxyurea are useful in ameliorating symptoms in SD disease and in sickle cell anaemia. ${ }^{6}$ Although transfusion programmes abolish symptoms in these patients, this child's case illustrates that the dangers of iron overload should always be remembered.

\section{ACKNOWLEDGEMENTS}

We would like to thank Mr S Ladva, St Mary's Hospital, for carrying out the ultrastructural examination of the spleen.

\section{Authors' affiliations}

P M C Jiskoot, Department of Histopathology, St Mary's Hospital, Praed Street, London W2 1NY, UK

C Halsey, Department of Haematology, St Mary's Hospital

R Rivers, Department of Paediatrics, St Mary's Hospital

B J Bain, St Mary's Hospital Campus of Imperial College Faculty of Medicine, London W2 INY, UK

B S Wilkins, Department of Histopathology, Royal Victoria Infirmary, Newcastle upon Tyne NE1 4LP, UK

Correspondence to: Dr B S Wilkins, Department of Histopathology, Royal Victoria Infirmary, Newcastle upon Tyne NE1 4LP, UK; bridget. wilkins@nuth.northy.nhs.uk

Accepted for publication 28 August 2003

\section{REFERENCES}

1 Gee BE, Platt OS. Sickle reticulocytes adhere to VCAM-1. Blood 1995;85:268-74.

2 Schiffman FJ, Weiss L, Cadman EC. Erythrophagocytosis by venous sinus endothelial cells of the spleen in auto-immune haemolytic anaemia. Haematol Rev 1988;2:327-43.

3 Ferreira JA, Feliu E, Rozman C, et al. Morphologic and morphometric light and electron microscopic studies of the spleen in patients with hereditary spherocytosis and autoimmune haemolytic anaemia. Br J Haematol 1989;72:246-53.

4 Buckley PJ, Dickson SA, Walker WS. Human splenic sinusoidal lining cells express antigens associated with monocytes, endothelial cells and T lymphocytes. J Immunol 1985; 134:2310-15.

5 Arber DA, Strickler JG, Chen Y-Y, et al. Splenic vascular tumours: a histologic, immunophenotypic and virologic study. Am J Surg Pathol 2000;24:827-35.

6 Udden MM, Lo MN, Sears DA. Successful hydroxyurea treatment of a patient with SD haemoglobinopathy. Am J Haematol 1999;60:84-5. 